\title{
Assessment of fear and anxiety associated behaviors, physiology and neural circuits in rats with reduced serotonin transporter (SERT) levels
}

Philip L. Johnson 1,2, Andrei I. Molosh', ${ }^{2,3}$, Lauren M. Federici, ${ }^{1,2,4}$, Cristian Bernabe ${ }^{1,2,4}$, David Haggerty (1)', Stephanie D. Fitz ${ }^{3}$, Eugene Nalivaiko ${ }^{5}$, William Truitt ${ }^{1,2}$ and Anantha Shekhar ${ }^{2,3}$

\begin{abstract}
Genetic variation in serotonin transporter (SERT) that reduces transcriptional efficiency is associated with higher anxiety and fear traits and a greater incidence of post traumatic stress disorder (PTSD). Although previous studies have shown that rats with no expression of SERT (SERT ${ }^{-/}$) have increased baseline anxiety behaviors, SERT ${ }^{+/-}$rats with low SERT expression (and more relevant to the clinical condition with low SERT expression) do not. Yet, no systematic studies of fear acquisition/extinction or their underlying neural mechanisms have been conducted in this preclinical genetic SERT ${ }^{+/-}$model. Here we sought to determine if SERT ${ }^{+/-}$or SERT ${ }^{-1-}$, compared to wildtype, rats would show exacerbated panic responses and/or persistent conditioned fear responses that may be associated with PTSD or phobia vulnerability. Results: Only SERT ${ }^{-1-}$ rats showed increased baseline anxiety-like behaviors with heightened panic respiratory responses. However SERT ${ }^{+/-}$(also SERT ${ }^{-1}$ ) rats showed enhanced acquisition of fear and delayed extinction of fear that was associated with changes in serotonergic-related genes (e.g., reduced 5-HT1A receptor) and disrupted inhibition within the basolateral amygdala (BLA). Furthermore, the disrupted fear responses in SERT ${ }^{+-}$rats were normalized with 5HT1A antagonist infusions into the BLA. Enhanced acquisition and failure to extinguish fear memories displayed by both SERT ${ }^{-/-}$and $\mathrm{SERT}^{+/-}$rats are cardinal symptoms of disabling anxiety disorders such as phobias and PTSD. The data here support the hypothesis that reduced SERT function is a genetic risk that disrupts select gene expression and network properties in the amygdala that could result in vulnerability to these syndromes.
\end{abstract}

\section{Introduction}

Post traumatic stress disorder (PTSD) and panic disorder (PD) represent some of the most severe and disabling trauma/anxiety related disorders ${ }^{1}$. Severe and or repeated psychological trauma can result in PTSD, which is associated with symptoms such as persistent fear associated memories (e.g., flashbacks) that can

\footnotetext{
Correspondence: Philip L. Johnson (philjohn@iupui.edu)

${ }^{1}$ Department of Anatomy and Cell Biology, Indiana University School of Medicine, Indianapolis, IN, USA

${ }^{2}$ Stark Neurosciences Research Institute, Indiana University School of Medicine, Indianapolis, IN, USA

Full list of author information is available at the end of the article.
}

trigger panic attacks $(\mathrm{PA})^{2}$ and lead to avoidance of activities, places and stimuli that produce these flashbacks. In regards to $\mathrm{PD}$, the cardinal symptoms are unexpected and recurrent (uPA)'s that occur in the absence of a clear external trigger and are estimated to account for $\sim 40 \%$ of PA's ${ }^{3}$. Recurrent unexpected PAs can produce a conditioned avoidance response that occurs when people with PD are traumatized by the uPA's and begin to fear situations that are associated with the uPA's. This can then induce expected PA's ${ }^{3}$ and agoraphobia in $\sim 50 \%$ of humans with $\mathrm{PD}^{4}$. Although unexpected, PA's can be reliably induced in humans with PD with viscerosensory associated stimuli such as 
5-7\% hypercapnic gas exposure ${ }^{5-7}$, which do not induce PAs in healthy controls at these concentrations. The relevance is that subtle increases in $\mathrm{CO}_{2}$ in the blood caused by hypoventilation or holding one's breath result in acidosis in peripheral and central brain structures that initially results in an increase in respiration activity to help "blow off" excess $\mathrm{CO}_{2}$ [see review ${ }^{8}$. However, a sense of suffocation occurs if $\mathrm{CO}_{2}$ levels continue to increase, which also produces adaptive behavioral and autonomic responses that recapitulate symptoms of PA's. For example, higher concentrations of $20 \% \mathrm{CO}_{2}$ will induce symptoms consistent with PA's in healthy humans ${ }^{9}$ and also induce concentration dependent increases in fear in healthy humans that is greater (more severe) in humans with $\mathrm{PD}^{10}$. Thus there is evidence that the initial PD pathology is associated with an alteration in central neural pathways which renders them susceptible to uPA's when exposed to otherwise non panic inducing viscerosensory stimuli ${ }^{11}$.

In the US, there is evidence that the risk of being exposed to a severe trauma could be as high as $75 \%{ }^{12}$, yet PTSD occurs in only about $7 \%$ of the population ${ }^{13}$ [see also review ${ }^{14}$ ]. Therefore the risk of being traumatized is much higher than the prevalence of PTSD. This suggests that the majority of people have some resiliency to traumatic events, but others may be more vulnerable (e.g., genetic contributions). In regards to $\mathrm{PD}$, the prevalence in the general population is $\sim 2-5 \%^{4,15}$ with a strong heritability in first degree relatives $(\sim 11 \%)$ and monozygotic twins $(30-40 \%)^{16,17}$, suggesting that in this case there are clear genetic contributions. Consistent with this hypothesis is that in humans with PD a meta-analysis of candidate genes identified several replicable candidate genes ${ }^{18}$ such as serotonin transporter (SERT) polymorphisms which is associated with severity of PAs ${ }^{18,19}$. SERT reuptake inhibitors (SSRIs) are also the gold standard for treating severe anxiety/trauma disorder such as PD and PTSD $^{20,21}$. In 1996 Lesch and colleagues assessed anxiety traits in humans carrying a specific polymorphism in the promoter region of the SERT gene, where the dominant short (s) allelic variant reduces transcriptional efficiency of the SERT ${ }^{22}$, which is evidenced by reduced brain SERT mRNA levels ${ }^{23}$, and reduced binding ${ }^{24}$. It has been determined that humans with this SERT polymorphism have increased anxiety-associated traits ${ }^{22}$ and enhanced fear conditioned responses ${ }^{25,26}$. This specific SERT ssallele polymorphism is also associated with a higher risk of PTSD in humans exposed to high trauma ${ }^{27}$, and although it is not associated with a higher risk for $\mathrm{PD}^{27}$ it is associated with more severe $\mathrm{PA}^{\prime} \mathrm{s}^{29}$.

Among anxiety circuits, the basolateral amygdala (BLA) is a critical site where serotonin plays an important role in modulating anxiety and fear responses and is highly responsive to stressful stimuli ${ }^{30-34}$. The BLA also plays a critical role in fear conditioned responses [see reviews ${ }^{35,36}$ ]. Humans with the SERT polymorphism have enhanced baseline amygdala activity and reactivity to fearful stimuli that is likely a contributing factor to increased anxiety and fear-associated traits ${ }^{37,38}$. However humans with atrophy of the amygdala region, whom have disrupted fear conditioned responses, display similar if not worse panic responses to a $20 \% \mathrm{CO}_{2}$ challenge ${ }^{39}$, and in one case study an intact amygdala was not necessary for a subject to experience PA's ${ }^{40}$. Consistent with this finding, Schruers and colleagues determined that humans with the SERT s-allele polymorphism displayed less fear to a panicogenic $\mathrm{CO}_{2}$ challenge ${ }^{41}$. Taken together this suggests that the SERT polymorphism may not be associated with initial unexpected PAs that are the initial phase of $\mathrm{PD}$, but may predispose them to the later development of amygdala regulated conditioned responses such as agoraphobia.

Similar to human SERT polymorphism, a heterozygous null mutation of the SERT gene $\left(\mathrm{SERT}^{+-}\right)$is also associated with reduced transcriptional efficiency in rats ${ }^{42}$. Rats with complete loss of SERT $\left(\mathrm{SERT}^{-1-}\right.$ ) have high baseline anxiety associated behaviors, but the SERT ${ }^{+/-}$ rats have normal anxiety behaviors, which suggests that other risk factors such as acute or chronic stress may be needed to observe anxiety vulnerability ${ }^{43,44}$. In light of the SERT gene being a strong candidate gene associated with the severity of PA's, but not being associated with increase panic symptoms post a $\mathrm{CO}_{2}$ challenge, we assessed baseline anxiety; innate panic responses to a $\mathrm{CO}_{2}$ challenge (as well as cellular responses in anxiety associated neural circuits); and fear conditioned responses in $\mathrm{SERT}^{+/-}$and $\mathrm{SERT}^{-1-}$.

\section{Methods and materials \\ Animals}

SERT $^{-1-}$ Wistar rats were purchased from genOway (Lyon, France) and were cross bred with wildtype SERT $^{+/+}$Wistar rats to produce SERT ${ }^{+/-}$heterozygous Wistar Rats ${ }^{42}$. The behavior and gene array experiments were conducted on male $300-325 \mathrm{~g}$ rats, and the electrophysiological experiments male $150-200 \mathrm{~g}$ rats. All rats were housed individually in plastic cages under standard environmental conditions $\left(22^{\circ} \mathrm{C} ; 12 / 12\right.$ light/dark cycle; lights on at 7:00 a.m.) for 7-10 days prior to the surgical manipulations. Food and water were provided ad libitum. All experiments were conducted in accordance with the Guide for the Care and Use of Laboratory Animals, Eighth Edition (Institute for Laboratory Animal Research, The National Academies Press, Washington, DC, 2011) and the guidelines of the IUPUI Institutional Animal Care and Use Committee. 


\section{RT-PCR to assess SERT mRNA in dorsal/median raphe nucleus and Gene Array in BLA}

Rats were rapidly anesthetized via IsoFlurane, decapitated, and brains were removed and frozen in isopentane chilled with dry ice, then stored at $-80^{\circ} \mathrm{C}$. In a RNase free environment, frozen brains were sliced coronally at $300 \mu \mathrm{m}$ (coronal) using a cryostat, and sections were placed onto slides. The dorsal raphe nucleus (DRn) and median raphe nucleus (MRn) were dissected out of 3 adjacent sections and the BLA from 2 adjacent sections using a $1.0 \mathrm{~mm}$ Harris Micro-punch (Electron Microscopy Sciences) and RNA processing and RT-PCR analysis of custom TLDA were performed as previously described ${ }^{45}$. For DRn/MRn, comparative evaluation of quantitative real-time PCR was performed with validated Taqman probes (Assay ID: SERT; Rn00564737_m1 and beta actin; Rn00667869_m1, respectively, Applied Biosystems) using the Taqman gene expression master mix and $7900 \mathrm{HT}$ real-time PCR system (Applied Biosystems). Each sample was analyzed in triplicate, and beta actin was used as an internal standard. The BLA tissue was processed for serotonergic-related genes using the custom-designed TaqMan Low Density Array (TLDA), see supplemental table 1 for listing of genes. The gene expression panel was normalized using geNorm approach, which identified Gapdh, Ppia and Ppib (from the 9 endogenous control genes included in the custom TLDA) to be used for normalization, as previously described in ref. ${ }^{45}$.

The light and dark box test (LDBT), open field test (OFT), and elevated plus maze (EPM)

Details are provided in supplemental methods. All rats were handled 3 times a week for 3-5 min by experimenter prior to the day of behavioral assays. Briefly, the LDBT apparatus consisted of one lit compartment (50 lux) and one dark compartment, which were adjacent to each other with a small opening enabling the rat to transition between the boxes during $5 \mathrm{~min}$ test. The OFT arena had 4 squares forming the center; 12 squares forming the middle perimeter; and 20 squares forming the outer perimeter. On the test day, rats were placed in the center and the time spent in the different zones during the $5 \mathrm{~min}$ test. Both tests were video-recorded and scored using Anymaze video tracking software (Stoelting, Woods Dale, IL).

The elevated plus maze consisted of 2 long arms with no walls, an intersection, and 2 closed walls. On the test day, the animals were placed in the center area of the maze and allowed to explore the open and closed arms for $5 \mathrm{~min}$. The total amount of time spent in each arm was recorded directly to the computer from the infrared beam breaks.

\section{Gas infusion procedure for in vivo respiration activity measures}

All rats were handled 3 times a week for 3-5 min by experimenter prior to the day of gas infusions. Rats were

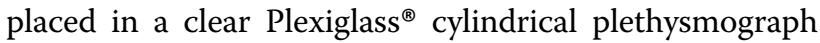
chamber with atmospheric air infused at a flow rate of $2.8 \mathrm{l} / \mathrm{min}$ using a Vetamac flowmeter (Rossville, IN) until a steady baseline respiration rate was noted. All rats had infusions of the following: (1) $5 \mathrm{~min}$ infusion of atmospheric gas $\left(<1 \% \mathrm{CO}_{2}, 21 \% \mathrm{O}_{2}, 79 \% \mathrm{~N}_{2}\right)$ for baseline measurements, then (2) either the control gas or experimental normoxic, hypercarbic gas $\left(7.5 \% \mathrm{CO}_{2}, 21 \% \mathrm{O}_{2}\right.$, $59 \% \mathrm{~N}_{2}$ ) for $5 \mathrm{~min}$, and finally, (3) $5 \mathrm{~min}$ infusion of atmospheric gas. A pressure amplifier (model 24PC01SMT, Honeywell Sensor, Golden Valley, MN) was connected to a Powerlab data 8/35 acquisition system (ADInstruments, Colorado Springs, CO) and respiration rate was assessed by calculated using LabChart software (ADInstruments), and sighing was also visualized using Labchart software. A sigh was defined as an initial respiration that immediately precedes an additional second deeper inspiration. The sigh is followed by an expiration that is larger than usual, and is often accompanied by a post sigh apnea ${ }^{46}$. Supplemental Fig. 1 illustrates the changes in the concentrations of $\mathrm{CO}_{2}$ and $\mathrm{O}_{2}$ that occur prior to, during and at offset of gas infusion.

Ninety min following the initiation of treatment, rats were anesthetized with an overdose of isoflurane then perfused transcardially with $0.05 \mathrm{M}$ phosphate buffered saline (PBS; $250 \mathrm{ml}$ ), followed by PBS containing $4 \%$ paraformaldehyde (PFA) and 3\% sucrose and the brains were removed and processed for immunohistochemistry as described in detail previously ${ }^{47}$.

\section{Immunohistochemistry procedures for c-Fos and SERT}

Free-floating sections were washed in $0.05 \mathrm{M}$ PBS for $10 \mathrm{~min} \times 3$ between initial incubation in $1 \% \mathrm{H}_{2} \mathrm{O}_{2}$ in PBS for $20 \mathrm{~min}$. Immunostaining for SERT protein and c-Fos protein was accomplished with sequential immunohistochemical procedures using (1) primary antibodies directed against SERT (rabbit anti-SERT polyclonal antibody, Cat. no. 24330, Immunostar, diluted 1,1000) and c-Fos (rabbit anti-c-Fos polyclonal antibody, Cat. no. sc-52, Ab-5, Santa Cruz Biotech., Santa Cruz, CA, USA; diluted 1:10,000) which were incubated on orbital shaker $12-14 \mathrm{~h}$ then washed in PBS prior to and in between $2 \mathrm{~h}$ incubations in: (1) biotinylated secondary antibodies; (2) avidin biotin complex kit; and (3) chromogen kit as described previously ${ }^{47}$.

\section{Densitometry of SERT-ir in dorsal raphe nucleus (DRn) and Counting of c-Fos-ir cells}

Selection of anatomical levels for analysis of SERT immunostaining in the DRn and c-Fos-immunostaining 
in anxiety circuits was conducted with reference to illustrations from a rat brain stereotaxic atlas ${ }^{48}$. Photomicrographs of the SERT immunostaining in the DRn were taken at $\times 400$ magnification using a DMLB Leica binocular brightfield microscope at 3 Bregma levels [i.e., $-7.4,-7.5,-7.6 \mathrm{~mm}$ from Bregma] for each rat. Densitometry analyses were done on grayscale inverted photographs using Adobe Photoshop version 16 for each Bregma level for each rat and combined prior to analyses. The WT mean represented $100 \%$ which was compared to $\mathrm{SERT}^{+/-}$and $\mathrm{SERT}^{-1-}$ values.

The numbers of c-Fos-ir cells were counted in the entire field of view at $\times 400$ magnification in brain regions implicated in innate panic responses [i.e., the dorsomedial hypothalamic nucleus (DMN) at $-2.80 \mathrm{~mm}$ Bregma and dorsolateral periaqueductal gray (DLPAG) at $-8.00 \mathrm{~mm}$ Bregma] and conditioned fear responses [i.e., central amygdaloid nucleus (CeA); basolateral amygdaloid nucleus (BLA), basolateral amygdaloid nucleus, ventral part (BLV); lateral amygdaloid nucleus (LA); and medial amygdaloid nucleus (MeA) at $-2.80 \mathrm{~mm}$ Bregma]. All cell counts were done by an observer that was blind to the experimental treatment of each animal.

\section{Photography}

Photomicrographs were obtained the Leica DMLB microscope connected to a Leica DFC 300 digital camera and Leica Applications Suite 4.1 for Windows.

\section{Fear conditioning protocol}

All rats were handled 3 times a week for $3-5$ min by experimenter prior to the day of behavioral assays. The fear-conditioning chamber has a grid floor composed of 6 stainless steel rods connect to a shock generator (Kinder Scientific, Poway, CA, USA). The fear conditioning protocol was 4 days long. On day 1 , rats were placed in the conditioning chamber and allowed to habituate for 10 min. On day 2 , test day 1 , the rats were placed back in the conditioning chamber and was exposed to 5 tone + shock pairings, with a $120 \mathrm{~s}$ inter-trial interval with a tone conditioned stimuli (CS: $80 \mathrm{~dB}, 20 \mathrm{~s})$ co-terminating with a single shock unconditioned stimuli (UC: $0.80 \mathrm{~mA}$, $500 \mathrm{~ms}$ ). On day 4, test day 2 , rats underwent an extinction paradigm where they were presented with 20 tone CS only with a $120 \mathrm{~s}$ inter-trial interval. All sessions were video-recorded and the total time spent freezing during the tones on all 2 test days was scored blind by the investigator Stephanie Fitz.

Injections of $5-\mathrm{HT}_{1 \mathrm{~A}}$ receptor agonist into $\mathrm{BLA}$ prior to fear acquisition and extinction of SERT ${ }^{+/-}$rats

All rats were handled 3 times a week for 3-5 min by experimenter prior to the day of behavioral assays. $\mathrm{SERT}^{+/-}$rats $(n=9)$ were anaesthetized by placing them in a closed Plexiglas ${ }^{\circledR}$ box that was connected to an isoflurane system (MGX Research Machine; Vetamic, Rossville IN, USA) and then with a nose cone connected to the same system during the stereotaxic surgery. Rats were placed into an ultra-precise stereotaxic instrument (Kopf Instruments, Tujunga, CA, USA) with the incisor bar set at $-3.3 \mathrm{~mm}$ and nose cone connected to the same system during the surgery. Two stainless steel guide cannulae (26 gauge, Plastics One, Roanoke, VA) were situated into guide cannulae holders fixed onto the stereotaxic arms. The 33 gauge injector was lowered into position of the BLA using coordinates (anterior, $-2.1 \mathrm{~mm}$; lateral, $\pm 5.0 \mathrm{~mm}$; ventral, $-8.5 \mathrm{~mm}$ ) according to a standard stereotaxic atlas of the adult rat brain ${ }^{48}$. The guide cannulae were secured into place using three $2.4 \mathrm{~mm}$ screws anchored into the skull along with cranioplastic cement. Following placement of dummy cannulae into the guide cannulae, rats were removed from the stereotaxic apparatus and allowed to recover for $72 \mathrm{~h}$ prior to experimental testing. SERT ${ }^{+/-}$rats received bilateral $200 \mathrm{~nL}$ injections of either artificial cerebrospinal fluid (aCSF, $n=5$ ) or $20 \mathrm{mM}$ 8-Hydroxy-2-(dipropylamino)tetralin hydrobromide (8-OH-DPAT, a $5-\mathrm{HT}_{1 \mathrm{~A}}$ agonist, Sigma, $n=4) 20 \mathrm{~min}$ prior to acquisition and recall/extinction at a rate of $100 \mathrm{~nL} / \mathrm{min}$ using $10-\mu \mathrm{l}$ Hamilton syringes attached to an infusion pump (Harvard Apparatus, model PHD 2000) and subsequently connected to the injection cannulae via polyethylene (PE 50) tubing (Fisher Scientific, Pittsburg, PA). Once the injection cannulae were securely placed into the rat, the infusion pump was turned on and set to automatically deliver $100 \mathrm{~nL} /$ site over $2 \mathrm{~min}$. Following the injection, the cannulae remained in place for an additional min before being removed. Smooth flow of the solutions via the tip of the injection cannulae was verified before and after each injection to ensure proper drug delivery.

\section{Electrophysiology}

Once anesthetized, brains were quickly dissected, and $350-\mu \mathrm{m}$ coronal slices were obtained as described earlier ${ }^{49}$. Briefly, slices were incubated in an oxygenated (95\% $\mathrm{O}_{2} / 5 \% \mathrm{CO}_{2}$ mixture) artificial cerebrospinal fluid (ACSF) of the following composition (in $\mathrm{mM}$ ): $130 \mathrm{NaCl}, 3.5 \mathrm{KCl}$, $1.1 \mathrm{KH}_{2} \mathrm{PO}_{4}, 1.3 \mathrm{MgCl}_{2}, 2.5 \mathrm{CaCl}_{2}, 10$ glucose, 30 $\mathrm{NaHCO}_{3}$ at room temperature for $\sim 1 \mathrm{~h}$ before the recording. Slices containing the BLA were then transferred to a recording chamber mounted on the stage of the upright Nikon E600FN microscope (Nikon Instruments Inc., Melville, NY) and perfused at rate of $2-3 \mathrm{ml} /$ min with ACSF heated to $30^{\circ} \mathrm{C}$. Whole-cell patch clamp recordings were obtained using standard techniques with borosilicate glass electrodes (resistance 3-5 M $\Omega$, WPI, Sarasota, FL) filled with a potassium gluconate-based solution of the subsequent composition (in $\mathrm{mM}$ ): 140 
potassium gluconate, $2 \mathrm{KCl}, 3 \mathrm{MgCl}_{2}, 10$ HEPES, 5 phosphocreatine, 2 potassium-ATP, 0.2 sodium-GTP) adjusted to $\mathrm{pH} 7.3$ with $\mathrm{KOH}$, and having an osmolarity of 285-295 mOsm. Whole-cell access resistance varied between 5 to $20 \mathrm{M} \Omega$ and was examined during each experiment; a change of less than $15 \%$ was acceptable. The data were obtained only from pyramidal neurons located in BLA. Whole-cell recordings were made with a Multiclamp 700B amplifier (Molecular Devices, Sunnyvale, CA) using the pClamp 10.3 software and a Digidata 1322 A interface (Molecular Devices, Sunnyvale, CA).

\section{Statistical analyses}

The following dependent variables were analyzed using an ANOVA with genotype as the main independent variable (i.e., light dark box test, open field and elevated plus maze, sighs, c-Fos-ir cells, SERT-ir densitometry, and electrophysiology data). Respiratory responses over time and fear conditioned freezing behavior was analyzed using a one way ANOVA with repeated measures with genotype as independent variable and time as the repeated measures. In the presence of significant effects, between and within subjects post-hoc tests were conducted using a Fisher's LSD or Dunnett's post-hoc test, respectively. Statistical significance was accepted with $p \leq 0.05$. All statistical analyses were done with SPSS 25 and Graphpad Prizm 7.0; and all graphs were generated using Graphpad Prizm 7.0 for Windows. Figureplates were made with CorelDraw X for Windows.

\section{Results}

\section{Genotyping and SERT mRNA expression in DRn/MRn and SERT immunohistochemistry in the DRn}

In order to verify the diminished SERT transcriptional efficiency of SERT ${ }^{+-}$and SERT ${ }^{-1-}$ rats, we measured SERT mRNA in micropunched tissue containing the $\mathrm{DRn} / \mathrm{MRn}$ region, which revealed that, compared to wildtype SERT ${ }^{+/+}$controls $(n=3), \mathrm{SERT}^{-/+}$rats $(n=5)$ had approximately a $40 \%$ reduction SERT mRNA and SERT mRNA levels were at the limit of detection for $\mathrm{SERT}^{-1-}$ rats $\left(n=6, \mathrm{~F}_{(2,11)}=83.1, p<0.001\right.$, Fig. 1a). We also assessed SERT protein expression with a densitometry analysis of SERT immunostaining in the DRn where compared to WT rats $(n=6), \mathrm{SERT}^{+/-}(n=6)$ and SERT $^{-1-}(n=6)$ rats had $\sim 57 \%$ and $\sim 88 \%$ reduction in SERT immunostaining, respectively $\left[\mathrm{F}_{(2,15)}=11.9, p=\right.$ 0.0008 , Fig. 1b], which is consistent with a previous characterization $^{42}$.

\section{Light dark box test, open-field behavior and elevated plus maze}

Baseline assessment of innate anxiety-associated behaviors revealed that, compared to both wildtype $\mathrm{SERT}^{+/+}$ rats $(n=8)$ and SERT ${ }^{+/-}$rats $(n=13)$, only SERT ${ }^{-/-}$rats
( $n=11)$ displayed reduced time spent: (1) in the light box $\left(\mathrm{F}_{(2,29)}=5.7, p=0.008\right.$, Fig. 1c); (2) in the center zone of open field $\left(\mathrm{F}_{(2,29)}=4.0, p=0.029\right.$, Fig. $\left.1 \mathrm{~d}\right)$; or in the open arm + transition zone of the elevated plus maze $\left(\mathrm{F}_{(2,29)}=\right.$ $4.5, p=0.019$, Fig. 1e). Compared to WT rats, SERT ${ }^{-1-}$ rats also had less transitions between light and dark box in LDBT $\left(\mathrm{F}_{(2,29)}=6.0, p=0.0065\right.$, data not shown $)$ and the number of entries into the open arm of EPM approached significance as being reduced $\left(\mathrm{F}_{(2,29)}=3.3, p=0.0511\right.$, data not shown). There was no difference in center time entries in OFT $\left(\mathrm{F}_{(2,29)}=0.7, p=0.515\right.$, data not shown).

\section{Respiratory responses to atmospheric versus $\mathrm{CO}_{2}$ challenge}

Assessments of respiratory activity in conscious freely moving rats revealed that, compared to wildtype SERT ${ }^{+/+}$ $(n=6$, one outlier detected with a Grubb's test, $p<0.05)$ and $\mathrm{SERT}^{+1-}(n=8), \mathrm{SERT}^{-1-}$ rats $(n=7)$ had an increased no. of sighs $\left(\mathrm{F}_{(2,18)}=5.4,0.014\right)$, compared to WT rats during atmospheric control gas infusions (Fig. 2a, see also supplemental Fig. 2a,b). Although there was no difference in sigh frequency during the $\mathrm{CO}_{2}$ challenge $\left(\mathrm{F}_{(2,19)}=3.1, p=0.071\right.$, Fig. $\left.2 \mathrm{~b}\right)$, in a followup experiment there was a significant genotype $\times$ time interaction detected on respiration rate during the $\mathrm{CO}_{2}$ challenge $\left(\mathrm{F}_{(22,308)}\right.$ $=1.6, p=0.047$, Fig. 2c, see also supplemental Fig. 2c). Specifically, posthoc analyses revealed that SERT ${ }^{-l-}$ rats $(n=11)$, but not $\mathrm{SERT}^{+/-}$rats $(n=13)$, displayed a higher respiration rate during $\mathrm{CO}_{2}$ challenge, compared to wildtype SERT ${ }^{+/+}$controls $(n=7)$.

\section{Cellular responses in innate panic and learned fear network following a $7.5 \% \mathrm{CO}_{2}$ challenge}

Briefly exposing rats to $7.5 \%$ hypercarbic gas increased the number of c-Fos-ir cells in brain regions implicated in innate panic responses [i.e., DMN: Kuskall Wallis ANOVA $=5.9, p=0.05)$ and also in the DLPAG: Kruskall Wallis ANOVA $=7.7, p=0.02$ ) in only the $\mathrm{SERT}^{-1-}$ rats (Fig. 2d)]. Within learned fear circuits, exposing rats to hypercarbic gas increased numbers of c-Fos-ir cells in the LA (Kruskall-Wallis ANOVA $=8.7, p=0.01$ ) of only $\mathrm{SERT}^{-1-}$ rats, but for the BLA this occurred in both $\mathrm{SERT}^{+/-}$and $\mathrm{SERT}^{-1-}$ rats (Kruskall-Wallis ANOVA $=$ 9.5, $p=0.001$, Fig. 2e).

\section{Fear conditioning behaviors}

On acquisition day all rats displayed increased freezing over time with repeated pairings of the conditioned stimulus (tone) with the unconditioned stimulus (shock). However, a more rapid acquisition was detected in both the SERT ${ }^{-1-}(n=8)$ and SERT ${ }^{+-}(n=12)$ rats, compared to wildtype $\mathrm{SERT}^{+/+}$controls $(n=6$, not genotype $\times$ tone interaction $\mathrm{F}_{(8,92)}=2.0, p=0.048$, Fig. 3a). On test day 2 (evidence of consolidation), there was no 


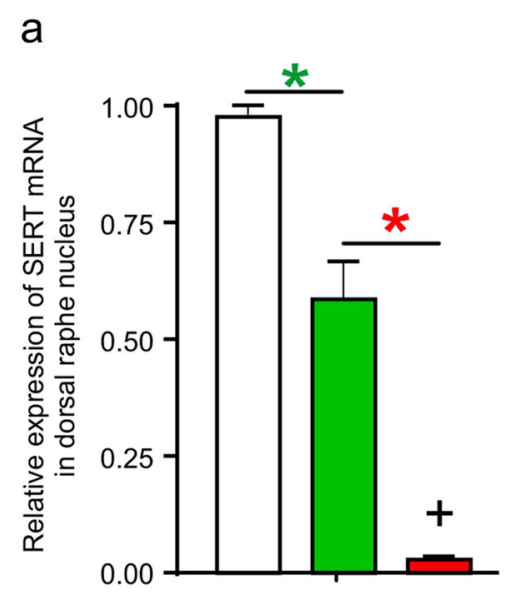

d

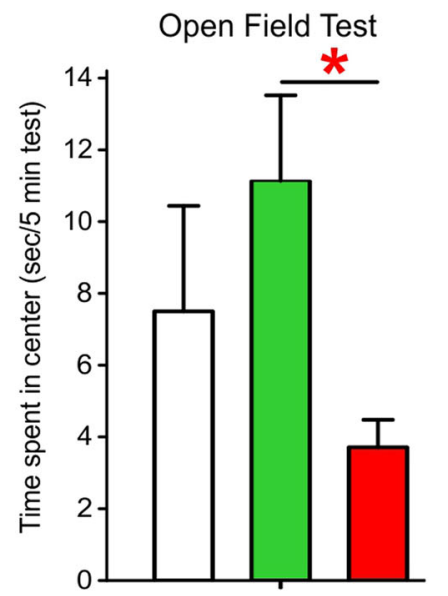

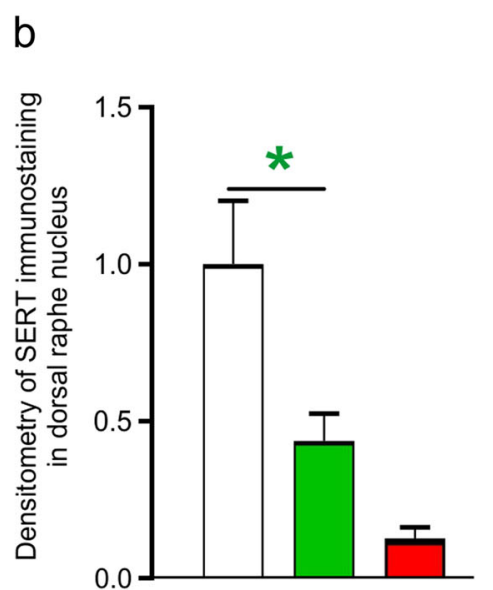

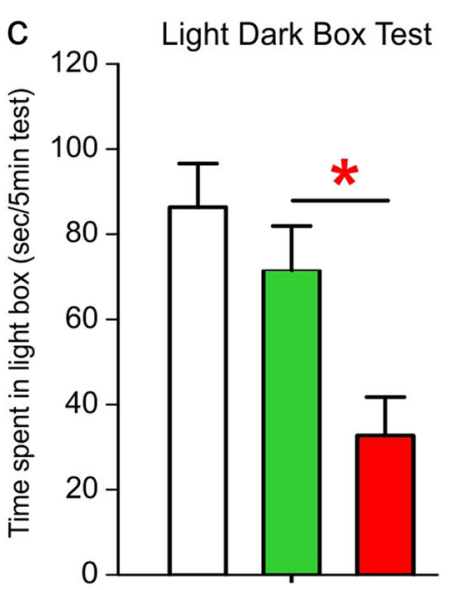

e

Elevated Plus Maze Test
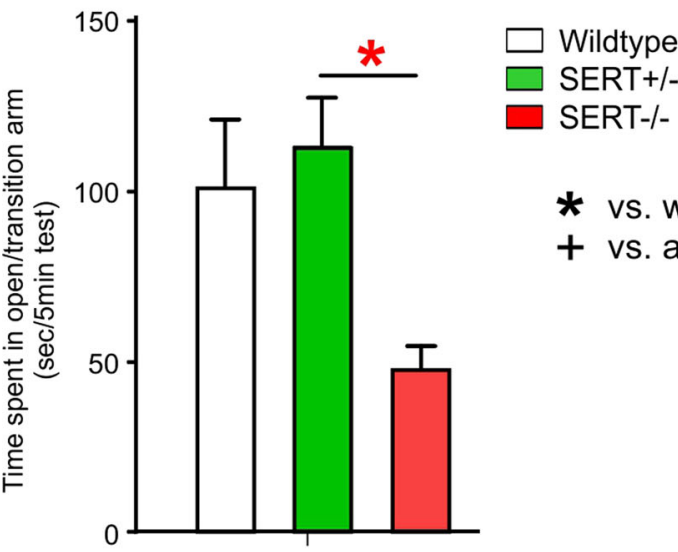

SERT-/-

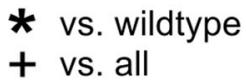

+ vs. all

Fig. 1 SERT mRNA in DRn/MRn and SERT immunohistochemistry in DRn. Bar graphs represent SERT (a) mRNA expression in the combined dorsal/median raphe nuclei; (b) densitometry analyses of SERT immunohistochemistry in the dorsal raphe nuclei and (c-e) baseline anxietyassociated behaviors between wildtype, SERT ${ }^{+-}$and SERT ${ }^{-/-}$genotypes: (c) duration of time in light box, compared to dark box; (d) time spent in center of an open field; and (e) time spent on the combined open arm and transition zone. Bars represent mean and error bars the standard error of the mean (SEM). Asterisks $\left(^{*}\right)$ indicates posthoc significance with a Fisher's LSD, $p<0.05$

significant genotype $\times$ tone interaction, $F_{(34,437)}=0.8, p=$ 0.80 but there was an overall genotype effect, $\mathrm{F}_{(2,23)}=3.6$, $p=0.044$ detected. Between subjects posthoc analyses revealed that there was no difference in recall between groups on tone 1 with no shock. However, the SERT ${ }^{-/-}$ and SERT ${ }^{+/-}$rats showed higher freezing on subsequent tones and had delayed extinction learning (Fig. 3b).

\section{Intrinsic and network properties of BLA principal neurons} of SERT ${ }^{+/-}$, SERT $^{-/-}$, and WT rats

We calculated number of action potentials induced by the injected current of the same value. The BLA neurons from SERT ${ }^{+/-}$and $\mathrm{SERT}^{-/-}$animals fired significantly higher number of evoked action potentials compared to the WT rats $\left[\mathrm{F}_{(2,30)}=6.04, p=0.006\right.$, Fig. 4a, see also supplemental Fig. 3a]. Additionally, we also observed significantly higher membrane input resistance between
WT $(n=12), \mathrm{SERT}^{+/-}(n=11)$ and $\mathrm{SERT}^{-1-}(n=10)$ groups $\left[\mathrm{F}_{(2,30)}=4.56, p=0.02\right.$, Fig. 4b]. Last, we also looked at BLA network properties by measuring amplitude and frequency of spontaneous excitatory (EPSCs) and inhibitory currents (IPSCs). We noticed a significant reduction of amplitude and frequency of spontaneous compound IPSCs in $\mathrm{SERT}^{+/-}$and SERT ${ }^{-1-}$ rats compared to WT [amplitude: $\mathrm{F}_{(2,30)}=4.41, p=0.021$; frequency: $\mathrm{F}_{(2,30)}=7.77, \quad p=0.002$, Fig. $4 c$, see also supplemental Fig. 3b]. No changes in amplitude and frequency of sEPSCs were observed [amplitude: $\mathrm{F}_{(2,29)}=$ $0.13, p=0.883$; frequency: $\mathrm{F}(2,29)=0,11, \quad p=0.896$, supplemental Fig. 3b, c).

\section{Custom serotonin-related gene TLDA}

Among the twenty-one serotonin related genes (see Suppl. Table 1) that were assessed within the BLA of WT, 
a

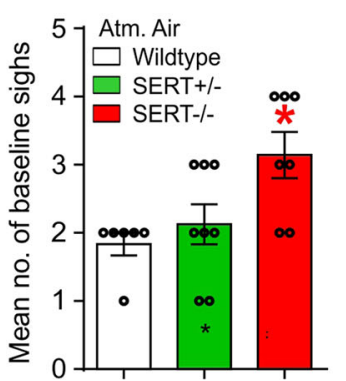

b

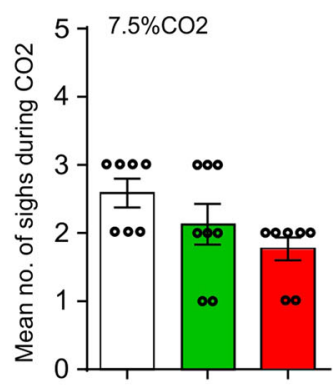

C

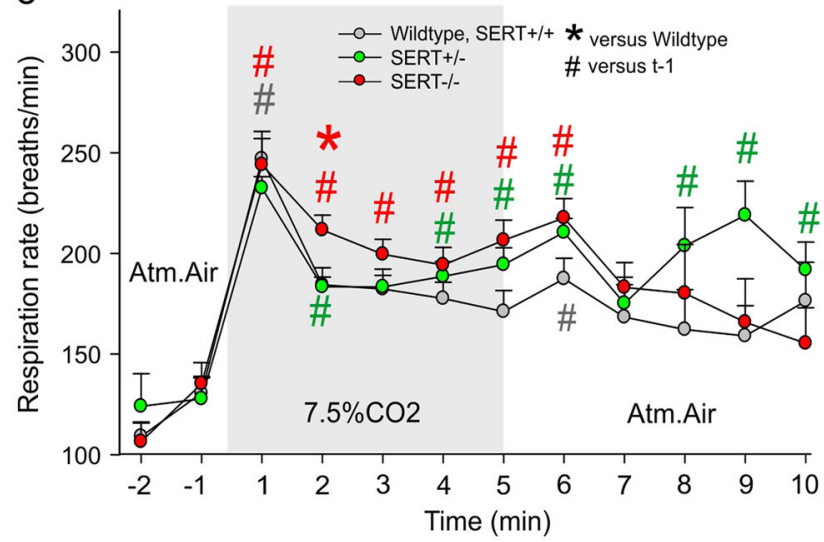

d

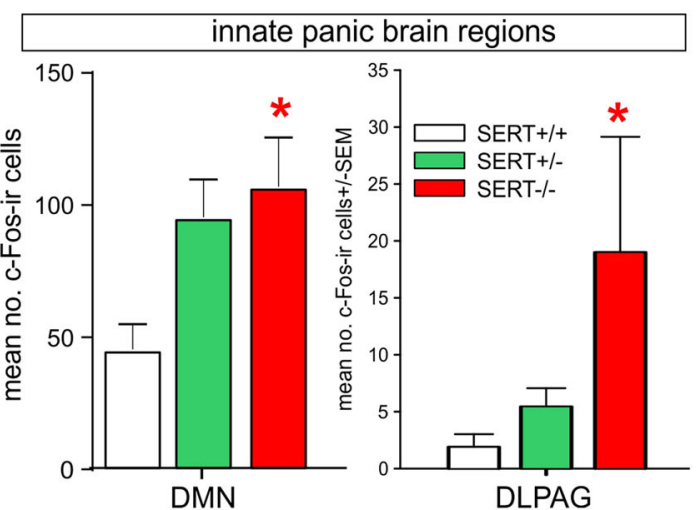

e

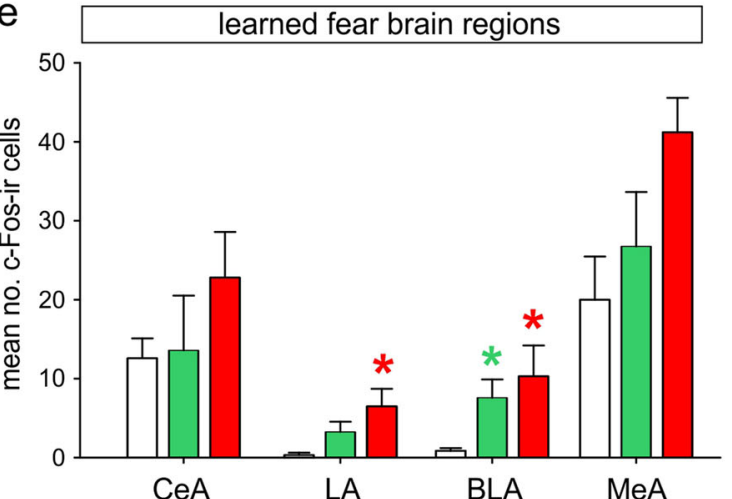

Fig. 2 Respiratory and cellular c-Fos responses to $\mathrm{CO}_{2}$ challenge. $\mathbf{a}$, $\mathbf{b}$ Represents bar graphs of the no. of sighs at baseline and during infusion of $7.5 \% \mathrm{CO}_{2}$ (normoxic). $\mathbf{c}$ Line graph represents the respiratory rate responses (breaths $/ \mathrm{min}$ ) for wildtype, $\mathrm{SERT}^{+/-}$and SER ${ }^{-1-}$ rats during atmospheric air infusions (non-shaded regions) and during hypercapnic gas $\left(7.5 \% \mathrm{CO}_{2}\right.$, normoxic air, shaded region) infusions. Asterisks $\left({ }^{*}\right)$ indicates significant between subjects effects with a Fishers LSD posthoc test protected by an ANOVA, and hastag(\#) indicates significant within subject time effects with a Dunnett's test protected by a repeated measures one way ANOVA. $\mathbf{d}$, e bar graph represents ex vivo cellular responses (evidenced by numbers of cells with nuclear expression of c-Fos protein immunostaining) in the dorsomedial hypothalamic nucleus (DMN), dorsolateral periaqueductal gray (DLPAG) and amygdala nuclei following exposure to $7.5 \% \mathrm{CO} 2$ in wildtype, SERT ${ }^{+-}$and SERT ${ }^{-1}$ rats. Error bars represent the SEM

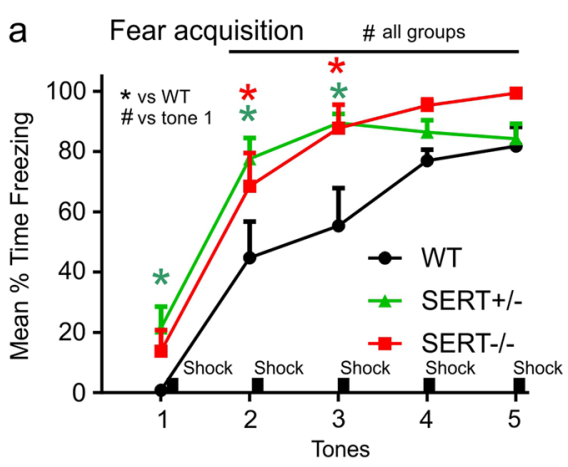

b Fear recall/extinction

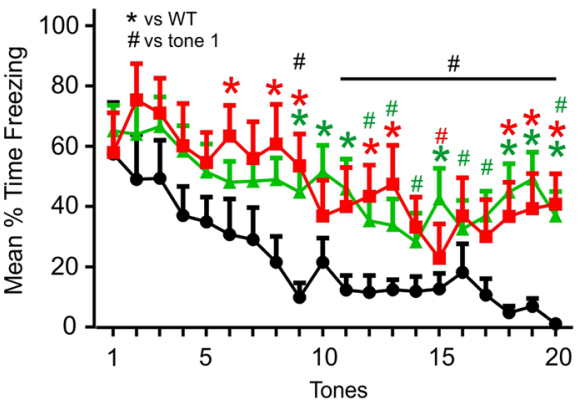

Fig. 3 Fear conditioned behaviors. Line graph represents the mean duration of freezing of wildtype $(n=6)$, SERT ${ }^{+/-}(n=12)$ and SERT ${ }^{-/-}(n=8)$ rats during a presentation of an acoustic tone on the following days: (a) acquisition of conditioning with 5 tones followed by 5 mild shocks on day 1 ; (b) evidence of consolidation on day 2 with initial tone and no shock and extinction learning with subsequent tones and no shock. Asterisks $(*)$ and hastag(\#) indicates significant between subjects effects with a Fishers LSD posthoc test or within subject differences over time with a Dunnett's test (versus tone one, baseline) protected by a repeated measures one way ANOVA. Error bars represent the SEM 

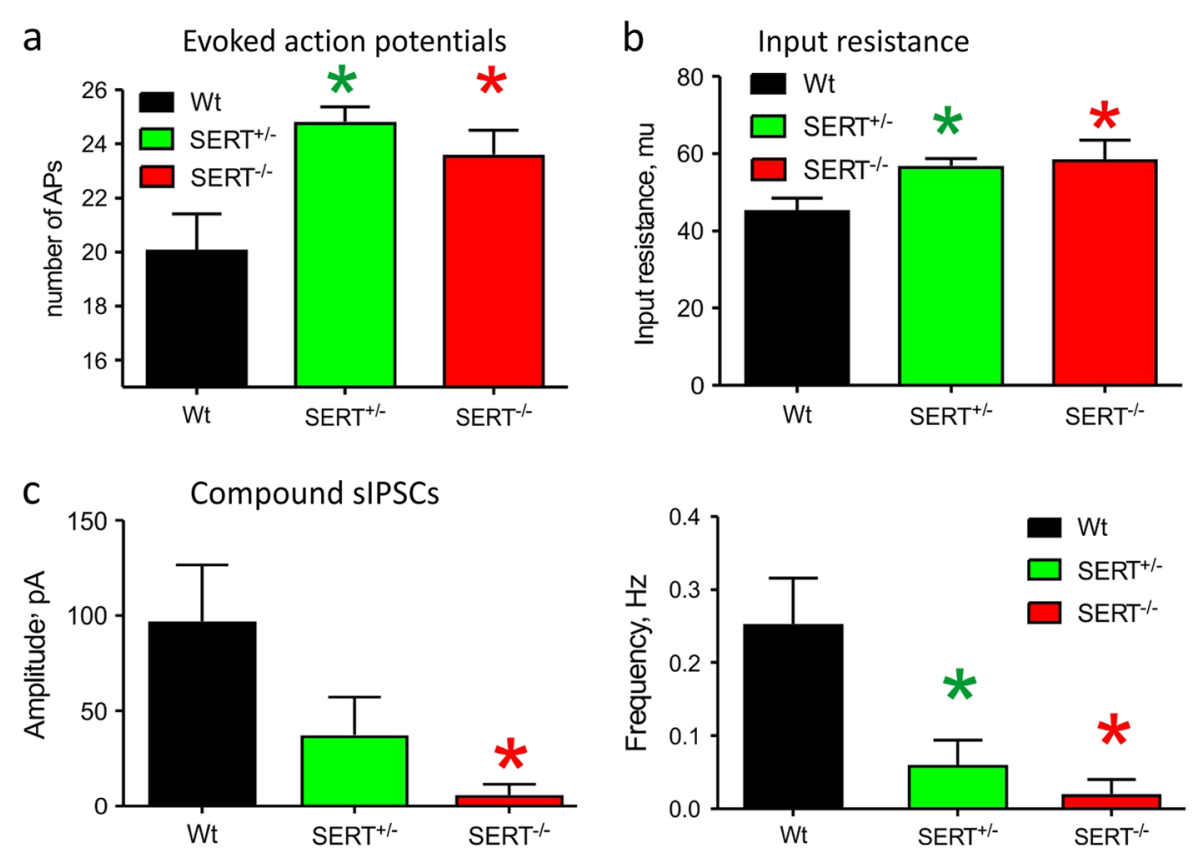

Fig. 4 Intrinsic and network properties of BLA principal neurons. a bar graph summarizing the number of evoked action potentials of WT, $\mathrm{SERT}^{+/-}$and SERT ${ }^{-1-}$ rats; (b) Bar graph represents input resistance of the BLA principal neurons of wildtype $(n=12), \mathrm{SERT}^{+/-}(n=11)$ and SERT ${ }^{-/-}$ $(n=10)$ rats; (d) representative spontaneous activity recordings in voltage-clamp mode from BLA neurons of WT, SERT ${ }^{+/-}$and SERT ${ }^{-/-}$rats, (e) bar graphs summarizing amplitude and frequency of spontaneous compound IPSCS of WT, SERT ${ }^{+/-}$and SERT ${ }^{-/-}$rats; (f) bar graphs summarizing amplitude and frequency of sEPSCS of WT, SERT ${ }^{+-}$, and SERT ${ }^{-1-}$ rats. Error bars represent the SEM

$\mathrm{SERT}^{+/-}$, and SERT ${ }^{-/-}(\mathrm{n}=5 /$ genotype $)$ expression of four genes, Htr2b, Htr3b, Htr5b and Slc6a4 (SERT) were below detection limits $(\mathrm{Ct}>34)$ in the BLA and were removed from analysis. The relative expression of remaining 17 genes had significant resulted in significant main effects of Genotype, Gene and Genotype $\times$ Gene interaction (2way ANOVA $F_{2,170}=4.925, P=0.0083$; $\mathrm{F}_{16,170}=4.516, P<0.0001$; and $\mathrm{F}_{23,170}=1.641, P=0.0241$, respectively). Seven genes were differentially express between genotypes (Fig. 5 and Suppl. Table 1). Expression of the $5-\mathrm{HT}_{1 \mathrm{~A}}$ receptor gene (Htrla) was significantly reduced compared to WT in both $\mathrm{SERT}^{+/-}$and SERT ${ }^{-1-}$ groups (Tukey's $\mathrm{p}=0.0099$ and 0.0003 , respectively). $\mathrm{SERT}^{+/-}$and SERT ${ }^{-1-}$ groups had significantly increased expression, compared to WT, of Htr1d (5- $\mathrm{HT}_{1 \mathrm{~d}}$ receptor), Htr2c $\left(5-\mathrm{HT}_{2 \mathrm{c}}\right.$ receptor) and Slc18a1 (vesicular monoamine transporter) genes (Tukey's $p \leq 0.022$ ). Additionally, expression of Htr4 (5- $\mathrm{HT}_{4}$ receptor) and Htr6 (5HT6 receptor) genes were both significantly increased in the SERT ${ }^{+/-}$group compared to WT (Tukey's $p=0.0215$ and 0.022 , respectively).

Injections of $5-\mathrm{HT}_{1 \mathrm{~A}}$ receptor agonist into BLA prior to fear acquisition and extinction of SERT ${ }^{+/-}$rats

On acquisition day there was no difference in freezing acquisition between $\mathrm{SERT}^{+/-}$rats with bilateral injections

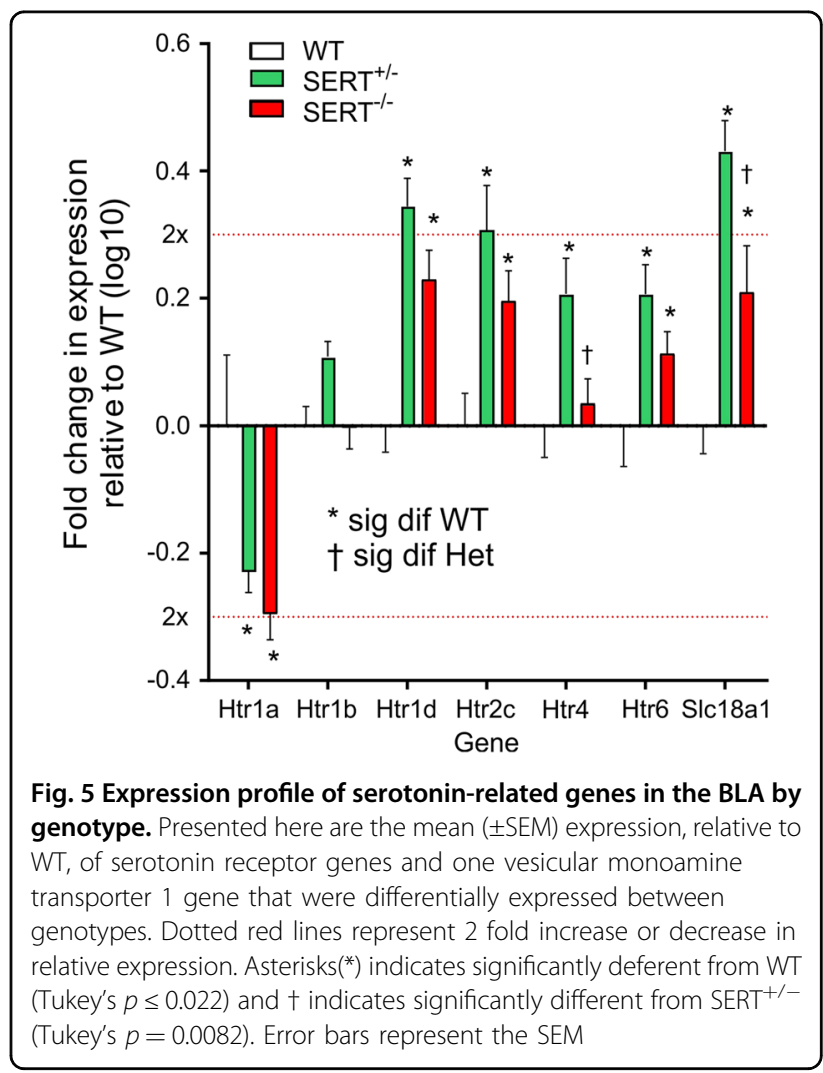




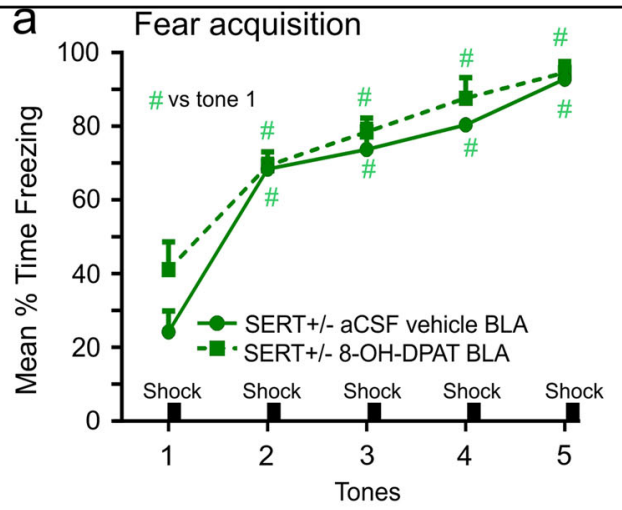

b Fear recall/extinction

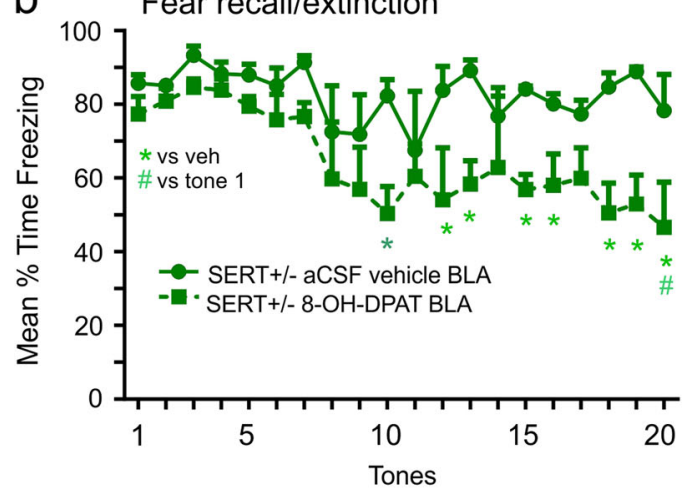

C Injection sites

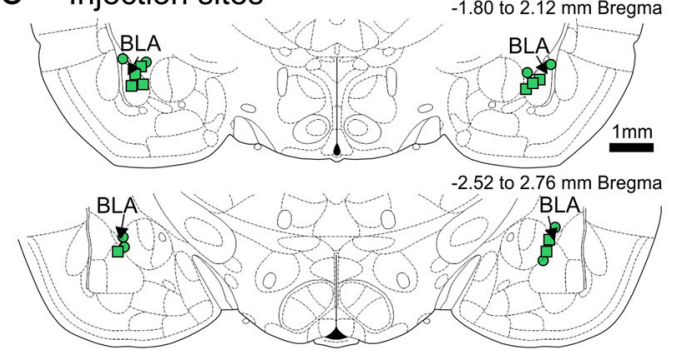

Fig. 6 Fear conditioned behaviors in SERT ${ }^{+/-}$rats following 5$\mathrm{HT}_{1 \mathrm{~A}}$ receptor agonist injections in the BLA. Line graph represents the mean duration of freezing of SERT ${ }^{+-}(n=4)$ rats with bilateral injections of either artificial cerebral spinal fluid vehicle $(n=5)$ or the 5- $\mathrm{HT}_{1 \mathrm{~A}}$ receptor agonist 8-OH-DPAT into the BLA prior to (a)

acquisition of conditioning with 5 tones followed by 5 mild shocks on day 1 ; (b) evidence of consolidation on day 2 with initial tone and no shock and extinction learning with subsequent tones and no shock. * and \# indicates significant between subjects effects with a Fishers LSD posthoc test or within subject differences over time with a Dunnett's test (versus tone one, baseline) protected by a repeated measures one way ANOVA. (c) Coronal illustration of a Standard stereotaxic atlas of the rat brain with green circle and green square symbols indicating injection cannula for SERT ${ }^{+/-}$rats injected with either vehicle or 8-OHDPAT, respectively. Error bars represent the SEM

of artificial cerebrospinal fluid vehicle $(n=5)$ or with 8OH-DPAT $(n=4)$ into the BLA (Fig. 6a, overall tone effect detected $\mathrm{F}_{(4,28)}=46.0, p<0.0001$, but no overall treatment effect or treatment $\times$ tone interaction $\mathrm{F}_{(4,28)}=$
$0.9, p=0.492$ ). On test day 2 , there was no significant treatment $\times$ tone interaction, but there was an overall treatment effect, $\mathrm{F}_{(1,7)}=8,5, p=0.022$ detected. Between subjects posthoc analyses revealed that there was no difference in recall between groups on initial tones with no shock. However, the SERT ${ }^{+/-}$rats pretreated with 8-OHDPAT into the BLA displayed decreased freezing on subsequent tones (Fig. 6b). Histology verified that all injections were within BLA region (Fig. 6c).

\section{Discussion}

Here we first confirmed that that there was reduced transcription of SERT mRNA and protein expression within the DRn and MRN of SERT ${ }^{+/-}$rats and at the limit of detection in $\mathrm{SERT}^{-1-}$ rats, then also confirmed that SERT $^{-1-}$ rats, but not SERT ${ }^{+/-}$rats, had high baseline anxiety associated behaviors, which are both consistent with previous reports ${ }^{42-44}$. We then exposed SERT ${ }^{+/-}$ and $\mathrm{SERT}^{-/-}$rats to a viscerosensory challenge [i.e., $5 \mathrm{~min}$ 7.5\% hypercapnic gas exposure] that induces PA's in the majority of humans with PD, but not healthy controls $^{50-52}$. Only SERT ${ }^{-1-}$ rats showed evidence of panic vulnerability which was evidenced by increased baseline sighing and heightened tachypnea to the hypercapnic challenge, which was also associated with increased cellular responses in two brain regions [i.e., the DPAG and $\mathrm{DMH}$ ] where PA's can be induced in human by electrical stimulation ${ }^{53-55}$ and where panic associated behaviors and physiological responses can be induced in rats following pharmacological disinhibition ${ }^{56-59}$. The hypothesis that the high baseline sighing and increased respiratory rate responses to $7.5 \% \mathrm{CO}_{2}$ challenge in only $\mathrm{SERT}^{-1-}$ rats potentially indicates panic vulnerability is consistent with clinical data. Specifically, a meta-analysis of baseline respiratory parameters in PD determined that PD was associated with higher baseline rate of sighing which may a hyper responsive reaction to increases in acidosis, a suffocation signal ${ }^{60}$. This is also consistent with symptoms such as dyspnea, feeling out of breath, or suffocating during PAs, and that PA's can be reliably induced in humans with PD with 5-7\% hypercapnic gas exposure ${ }^{5-}$ 7. The lack of differences in sighing post $\mathrm{CO}_{2}$ is most likely due to the rapid increase in respiration rate in all rats, but that was also hyperactive in SERT ${ }^{-1-}$ rats. These $\mathrm{SERT}^{+/-}$data are also consistent with humans with the SERT s-allele polymorphism not displaying increased panic symptoms following a panicogenic $\mathrm{CO}_{2}$ challenge ${ }^{41}$.

Assessment of cellular responses within the amygdala post $\mathrm{CO}_{2}$ revealed that both $\mathrm{SERT}^{-1+}$ and $\mathrm{SERT}^{-/-}$rats had significant increases within the BLA, compared to WT rats. This was an interesting observation since previous studies have shown that even high concentrations of $20 \% \mathrm{CO}_{2}$ which induces panic associated behaviors and physiology in control rats ${ }^{61-63}$, does not increase c-Fos 
responses in the amygdala ${ }^{62}$. Because we have noted an increase in number of c-Fos positive cells in the BLA which plays a critical role in fear conditioned responses [see reviews ${ }^{35,36}$, we next assessed cue induced fear conditioned responses. Compared to WT rats, both $\mathrm{SERT}^{+/-}$and SERT ${ }^{-1-}$ rats displayed similar increases in the acquisition of cue induced freezing and resistant fear extinction $48 \mathrm{~h}$ later. These SERT ${ }^{+/-}$data are consistent with humans with the SERT s-allele polymorphism having enhanced fear conditioned responses ${ }^{25,26}$ and being associated with a higher risk of PTSD in humans exposed to high trauma ${ }^{27}$. These data suggest that although SERT $^{+/-}$rats are not vulnerable to $\mathrm{CO}_{2}$ induced panic, they are prone to acquiring phobias which is a conditioned avoidance response that occurs when people with PD begin to fear situations/stimuli that are associated with PA's.

Since the SERT s-allele polymorphism is also associated with enhanced baseline amygdala activity and reactivity to fearful stimuli; ${ }^{37,38}$ we next assessed the basic and network properties of BLA principal neurons. Here both $\mathrm{SERT}^{+/-}$and $\mathrm{SERT}^{-1-}$ rats show a reduction in the inhibition within the BLA which was also associated with enhanced evoked action potentials. Overall, these data suggest that disruption of SERT transcription in both $\mathrm{SERT}^{+/-}$and $\mathrm{SERT}^{-/-}$rats induces a prolonged presence of serotonin in the synapses and the extrasynaptic space which disrupts the function of the local amygdala GABAergic network, which may also contribute in the overall increase of the excitability of the BLA neurons. Extracellular levels of 5-HT increase rapidly within the BLA during fear conditioning ${ }^{64}$ and high concentrations or prolonged application of 5-HT reduce the frequency and amplitude of spontaneous IPSP $/ \mathrm{Cs}^{65}$. Prolonged increases in extracellular 5-HT also occur in response to inescapable stress ${ }^{66}$, which may contribute to a net loss of local GABA inhibition, as seen here, and subsequent increase in excitation of glutamatergic projection neurons following evoked responses or in response to threat. In order to gain more insights into molecular serotonergic network changes in the BLA of each genotype we next assessed local expression of serotonergic associated genes. Here we observed similar changes in gene expression in both $\mathrm{SERT}^{+/-}$and SERT ${ }^{-1-}$ rats, which correlated with abnormalities in fear condition behaviors, but not with baseline anxiety or panic vulnerability to $\mathrm{CO}_{2}$ challenge. Specifically, these genotypes were associated with an approximately 2 fold reduction in the 5 -HT1A receptor (Htr1a), and an $\sim 2$ fold increase in the 5-HT2C (Htr2c) and 5HT1d $(H t r 1 d)$ receptor. Within the amygdala 5-HT receptor subtypes mediate both excitatory and inhibitory actions on GABAergic interneurons and glutamatergic projection neurons ${ }^{67}$. Glutamatergic neurons in the BLA express both 5-HT1A and 5-HT2C receptors ${ }^{67,68}$, which, respectively, are inhibitory and excitatory metabotropic receptors. In regards to fear conditioning, 5-HT1A agonist injections into the BLA region will reduce fear conditioned freezing responses in rats ${ }^{69}$ and in hamsters ${ }^{70}$, which is consistent with our data where injecting a 5HT1A agonist into the BLA of a SERT ${ }^{+/-}$enhanced fear extinction. Conversely, BLA injections of a selective 5HT2C antagonist can attenuate fear conditioned behaviors $^{71}$. Thus the decreased expression of the 5-HT1A receptor and increased expression of the 5-HT2C receptor could shift the effects of 5-HT release onto glutamatergic neurons to being more excitatory and thus enhance fear acquisition. During fear extinction the infralimbic region of the prefrontal cortex plays a critical role in enhancing fear extinction partially through inhibition of the BLA glutamatergic neurons ${ }^{72-75}$. Thus, chronic excitatory effects of 5-HT onto glutamatergic BLA neurons of $\mathrm{SERT}^{+/-}$and SERT ${ }^{-1-}$ rats may interfere with inhibitory influence to induce deficits in safety learning. Overall, this expression profile could partially explain enhanced evoked action potentials of glutamatergic neurons in the BLA of SERT ${ }^{+/-}$and $\mathrm{SERT}^{-/-}$rats.

\section{Conclusions}

Our data are consistent with previous experiments where depleting 5-HT levels in the BLA region diminishes fear conditioned behaviors ${ }^{76}$. Although only the SERT ${ }^{-1-}$ rats showed a panic vulnerability to $\mathrm{CO}_{2}$, and the SERT sallele polymorphism is not associated with increases in PA/PD incidence, it is interesting that reduced 5-HT1A binding within the amygdala of humans with $\mathrm{PD}^{77,78}$ which could explain an increased incidence of expected PAs and high phobia comorbidity and also that PAs are more severe in PD humans with the SERT s-allele polymorphism ${ }^{29}$. Overall, these data are also supportive of the hypothesis that increased 5-HT activity within the amygdala may be contributing to the pathophysiology of expected PA's, phobia vulnerability and PTSD ${ }^{64,79}$.

\section{Supplemental methods and results \\ $R T-P C R$ to assess SERT mRNA in dorsal/median raphe nucleus and gene array in BLA}

Rats were rapidly anesthetized via IsoFlurane, decapitated, and brains were removed and frozen in isopentane chilled with dry ice, then stored at $-80^{\circ} \mathrm{C}$. In a RNase free environment, frozen brains were sliced coronally at $300 \mu \mathrm{m}$ (coronal), using a cryostat, and sections were placed onto slides. The dorsal raphe nucleus $(\mathrm{DRn})$ and median raphe nucleus (MRn) were dissected out of 3 adjacent $300 \mu \mathrm{m}$ sections [from -7.0 to $-8.0 \mathrm{~mm}$ (DRn) and -7.5 to $-8.5 \mathrm{~mm}$ from bregma using a $1.0 \mathrm{~mm}$ Harris Micro-punch (Electron Microscopy Sciences) and were placed into $75 \mu \mathrm{l}$ of SurePrep ${ }^{\mathrm{TM}}$ TrueTotal $^{\mathrm{TM}}$ RNA purification buffer/kit to isolate RNA (Fisher Scientific). 
Samples were vortexed and Total RNA was determined using Nanodrop 1000. Extracted RNA was then reverse transcribed using the GeneAmp Gold RNA PCR kit (Applied Biosystems) at the following reaction conditions: $2.5 \mu \mathrm{M}$ Oligo-dT primer, $2.5 \mathrm{mM}$ magnesium, $250 \mathrm{mM}$ of each deoxynucleotide triphosphate, $0.5 \mathrm{U} / \mathrm{ml}$ of RNase inhibitor and final concentration of $0.75 \mathrm{U} / \mu \mathrm{l}$ of MuLV reverse transcriptase. The reverse transcription conditions were $10 \mathrm{~min}$ at room temp, $15 \mathrm{~min}$ at $42^{\circ} \mathrm{C}, 10 \mathrm{~min}$ at $68^{\circ}$ $\mathrm{C}$ and $5 \mathrm{~min}$ at $95^{\circ} \mathrm{C}$ and produced $\sim 25 \mu \mathrm{l}$ of product. Comparative evaluation of quantitative real-time PCR was performed with validated Taqman probes (Assay ID: SERT; Rn00564737_m1 and beta actin; Rn00667869_m1, respectively, Applied Biosystems) using the Taqman gene expression master mix and 7900HT real-time PCR system (Applied Biosystems). Each sample was analyzed in triplicate, and beta actin was used as an internal standard.

The BLA region was bilaterally dissected from two consecutive $300 \mu \mathrm{m}$ coronal sections and tissue was processed for serotonergic-related genes using the customdesigned TaqMan Low Density Array (TLDA), see supplemental Table 1 for listing of genes. RNA processing and RT-PCR analysis of custom TLDA were performed as previously described ${ }^{45}$. The gene expression panel was normalized using geNorm approach, which identified Gapdh, Ppia and Ppib (from the 9 endogenous control genes included in the custom TLDA)to be used for normalization, as previously described $\mathrm{in}^{45}$.

The light and dark box test (LDBT) and open field test (OFT)

The LDBT apparatus consisted of one lit compartment $(45 \times 32 \times 32 \mathrm{~cm}, 50$ lux; light box $)$ and one dark compartment $(30 \times 32 \times 32 \mathrm{~cm}, 5$ lux $)$, which were adjacent to each other. A small opening $(10 \times 15 \mathrm{~cm})$ enabled the rat to transition between the boxes. On the test day, rats were placed in the light compartment and the time spent in each compartment during the 5 min test.

The OFT covered an area of $90 \mathrm{~cm} \times 90 \mathrm{~cm}$, with $40 \mathrm{~cm}$ high walls which was divided into a $6 \times 6$ grid of equallysized squares using black tape (36 total squares) with 4 squares forming the center; 12 squares forming the middle perimeter; and 20 squares forming the outer perimeter. On the test day, rats were placed in the center and the time spent in the different zones during the $5 \mathrm{~min}$ test. Both tests were video-recorded and scored using Anymaze video tracking software (Stoelting, Woods Dale, IL).

\section{Elevated plus maze}

The elevated plus maze (Hamilton-Kinder San Diego, CA) is $111.76 \mathrm{~cm}$ wide $\mathrm{x} 111.76 \mathrm{~cm}$ deep $\mathrm{x} 85.1 \mathrm{~cm}$ tall and each arm is $10.79 \mathrm{~cm}$ wide and $50.16 \mathrm{~cm}$ long, intersection is $10.79 \mathrm{~cm}$ by $10.79 \mathrm{~cm}$, closed walls are $40.00 \mathrm{~cm}$ high. On the test day, the animals were placed in the center area of the maze and allowed to explore the open and closed arms for $5 \mathrm{~min}$. The total amount of time spent in each arm was recorded directly to the computer from the infrared beam breaks.

\section{Gas infusion procedure for in vivo respiration activity measures}

Rats were placed in a clear Plexiglass ${ }^{\circledast}$ cylindrical plethysmograph chamber (i.d. $95 \mathrm{~mm}$, length $260 \mathrm{~mm}$, volume $1.84 \mathrm{l}$, wall thickness $3 \mathrm{~mm}$ ) with atmospheric air infused at a flow rate of $2.8 \mathrm{l} / \mathrm{min}$ using a Vetamac flowmeter (Rossville, IN) until a steady baseline respiration rate was noted. A differential pressure amplifier (model 24PC01SMT, Honeywell Sensor, Golden Valley, MN) was connected $20 \mathrm{~cm}$ away from the start of the output line to a Powerlab data 8/35 acquisition system (ADInstruments, Colorado Springs, CO) for continuous monitoring of respiration. The second $\mathrm{T}$ arm connector was opened to the room air. All rats had infusions of the following: (1) 5 min infusion of atmospheric gas $\left(<1 \% \mathrm{CO}_{2}, 21 \% \mathrm{O}_{2}, 79 \%\right.$ $\mathrm{N}_{2}$ ) for baseline measurements, then (2) either the control gas or experimental normoxic, hypercarbic gas $\left(7.5 \% \mathrm{CO}_{2}\right.$, $21 \% \mathrm{O}_{2}, 59 \% \mathrm{~N}_{2}$ ) for $5 \mathrm{~min}$, and finally, (3) $5 \mathrm{~min}$ infusion of atmospheric gas. Respiration rate was assessed by calculating the rate of pressure fluctuations inside the chamber using LabChart software (ADInstruments), and sighing was also visualized using Labchart software. A sigh was defined as an initial respiration that immediately precedes an additional second deeper inspiration. The sigh is followed by an expiration that is larger than usual, and is often accompanied by a post sigh apnea ${ }^{46}$. supplemental Fig. 1 illustrates the changes in the concentrations of $\mathrm{CO}_{2}$ and $\mathrm{O}_{2}$ that occur prior to, during and at offset of gas infusion.

\section{Gas infusion procedure for in vitro measurement of ambient $\mathrm{CO}_{2}$ and $\mathrm{O}_{2}$ concentrations}

Here we used state of the art sensors (www.CO2-meter. com, Osmond Beach, Fl) to measure changes in the concentrations of $\mathrm{CO}_{2}$ (Cozir, GSS IR LED sensor, 0$100 \%$ range with $3 \%+/-$ error) and $\mathrm{O}_{2}$ (UV light flux sensor, $0-25 \%$ range with $2 \%+/-$ error) within a clear custom built Plexiglass ${ }^{\circledR}$ cylindrical plethysmograph chamber (i.d. $95 \mathrm{~mm}$, length $260 \mathrm{~mm}$, volume $1.84 \mathrm{l}$, wall thickness $3 \mathrm{~mm}$ ) with atmospheric air infused for $5 \mathrm{~min}$; then $5 \mathrm{~min}$ of normoxic $7.5 \mathrm{CO}_{2}$; followed by $5 \mathrm{~min}$ of atmospheric air. The flow rate was $2.8 \mathrm{l} / \mathrm{min}$ using a Vetamac flowmeter (Rossville, IN). The battery operated sensors within the cages were interfaced with Gaslab data acquisition software (www.CO2-meter.com) on a Windows PC.

Initial in vitro assessments of $\mathrm{CO}_{2}$ and $\mathrm{O}_{2}$ concentration changes following a $5 \mathrm{~min}$ infusion of normoxic $7.5 \% \mathrm{CO}_{2}$ we determined that $\mathrm{CO}_{2}$ concentrations went from 
undetectable levels to $5 \%$ within $2 \mathrm{~min}$ and $7-7.5 \%$ 3-6 min and returned to baseline $4 \mathrm{~min}$ following the $\mathrm{CO}_{2}$ infusion $\left(\mathrm{F}_{(11,55)}=81.0, p<0.001\right.$, Suppl. Fig. $\left.1, n=6\right)$. Percent $\mathrm{O}_{2}$ concentrations went from $20.6 \% \mathrm{O}_{2}$ to $20.9 \%$ $\mathrm{O}_{2}$ during the $\mathrm{CO}_{2}$ challenge, then back to $20.6 \% \mathrm{O}_{2}$ following the $\mathrm{CO}_{2}$ gas challenge $\left(\mathrm{F}_{(11,55)}=86.0, p<0.001\right.$, Suppl. Fig. 1, $n=6$ ).

Supplemental Fig. 1-Line graphs in, respectively, represent the mean ambient concentrations of $\mathrm{CO}_{2}$ and $\mathrm{O}_{2}$ at 2 min baseline when atmospheric air was infused; 5 min post normoxic $7.5 \% \mathrm{CO}_{2}$ gas infusion; and $5 \mathrm{~min}$ of atmospheric air infusion. \# symbol represents within subjects over time significance with a 2 tailed Dunnett's posthoc test protected by a significant one way ANOVA with each gas treatment as the main factor. Error bars represent the SEM.

Supplemental Fig. 2-a-b represents representative sighs and sigh frequency between genotypes, respectively. (c) are representative respiratory responses to atmospheric air in controls and to $7.5 \% \mathrm{CO}_{2}$ in each genotype group.

Supplemental Fig. 3-a representative evoked action potential recordings from BLA neurons of WT, SERT ${ }^{+/-}$ and $\mathrm{SERT}^{-1-}$ rats; (c) representative spontaneous activity recordings in voltage-clamp mode from BLA neurons of WT, SERT ${ }^{+/-}$and $\mathrm{SERT}^{-/-}$rats, (c) bar graphs summarizing amplitude and frequency of sEPSCs of WT, $\mathrm{SERT}^{+l-}$ and $\mathrm{SERT}^{-1-}$ rats. Error bars represent the SEM.

\section{Shock sensitivity protocol}

In order to confirm there were no differences in shock sensitivity between genotypes, rats from each genotype group were placed in the same fear conditioning chambers as described previously. The rats were then exposed to a series of $500 \mathrm{~ms}$ shocks starting at $0.1 \mathrm{~mA}$ and increasing by $0.1 \mathrm{~mA}$ after each $20 \mathrm{~s}$ interval. The behavior was recorded for the duration of the experiments and the latency to induce a startle response was then used to determine shock sensitivity.

In this experiment the mean shock needed to induce a startle response was $\sim 0.4 \mathrm{~mA}$ with no difference noted between genotypes [Suppl. Fig. 4, WT, $n=6$; SERT $^{+/-}$ $n=5$; $\left.\mathrm{SERT}^{-l-} n=6 ; \mathrm{F}_{(2,14)}=0.04, p=0.96\right]$. This was also below the $0.8 \mathrm{~mA}$ shock used for fear conditioning experiment.

Supplemental Fig. 4-Bar graph represents the mean intensity of shock needed to induce a startle response between wildtype $(n=6), \mathrm{SERT}^{+/-}(n=5)$ and SERT ${ }^{-1-}$ $(n=5)$ rats. The arrow indicates the shock intensity used for fear conditioning experiment in Fig. 3. Error bars represent the SEM.

Supplementary Table 1 - List of the 21 serotonin related genes assessed in the BLA using a custom TaqMan RTPCR array microfluidic card.

\section{Acknowledgements}

We are respectively grateful to Andrea Cordoso for technical support on immunohistochemical experiments.

\section{Author details}

'Department of Anatomy and Cell Biology, Indiana University School of Medicine, Indianapolis, IN, USA. ${ }^{2}$ Stark Neurosciences Research Institute, Indiana University School of Medicine, Indianapolis, IN, USA. ${ }^{3}$ Department of Psychiatry, Indiana University School of Medicine, Indianapolis, IN, USA. ${ }^{4}$ Program in Medical Neurosciences, Indiana University School of Medicine, Indianapolis, IN, USA. ${ }^{5}$ School of Biomedical Sciences and Pharmacy, University of Newcastle, Newcastle, NSW, Australia

\section{Conflict of interest}

This work was supported by K01 AG 044466 to P.L.J., R01 MH 106568 to W.T., and R01 MH 065702 and MH 052619 to A.S. P.L.J. received a research grant from Janssen Research and Development, LLC to conduct experiments not related to data in this manuscript. Within the last 3 years A.S. received research grants from Johnson and Johnson and Eli Lilly and Co. for conducting preclinical studies that are unrelated to the present paper. The remaining authors declare that they have no conflict of interest.

\section{Publisher's note}

Springer Nature remains neutral with regard to jurisdictional claims in published maps and institutional affiliations.

Supplementary information accompanies this paper at (https://doi.org/ 10.1038/s41398-019-0368-y).

Received: 2 March 2018 Revised: 15 August 2018 Accepted: 5 October 2018 Published online: 22 January 2019

\section{References}

1. DSM-V Diagnostic and Statistical Manual-5th edn. (DSM - V). (American Psychiatric Association, Washington, DC, 2013).

2. Jensen, C. F., Peskind, E. R., Keller, T. W., McFall, M. E. \& Raskind, M. A. Comparison of sodium lactate-induced panic symptoms between panic disorder and posttraumatic stress disorder. Depress Anxiety 7, 122-125 (1998).

3. Shulman, I. D., Cox, B. J., Swinson, R. P., Kuch, K. \& Reichman, J. T. Precipitating events, locations and reactions associated with initial unexpected panic attacks. Behav. Res. Ther. 32, 17-20 (1994).

4. Kessler, R. C. et al. The epidemiology of panic attacks, panic disorder, and agoraphobia in the National Comorbidity Survey Replication. Arch. Gen. Psychiatry 63, 415-424 (2006).

5. Gorman, J. M. et al. Response to hyperventilation in a group of patients with panic disorder. Am. J. Psychiatry 141, 857-861 (1984).

6. Gorman, J. M. et al. Ventilatory physiology of patients with panic disorder. Arch. Gen. Psychiatry 45, 31-39 (1988).

7. Woods, S. W., Krystal, J. H., D'Amico, C. L., Heninger, G. R. \& Charney, D. S. A review of behavioral and pharmacologic studies relevant to the application of $\mathrm{CO}_{2}$ as a human subject model of anxiety. Psychopharmacol. Bull. 24, 149-153 (1988b).

8. Guyton, A. C. Textbook of Medical Physiology: W.B. Saunders Company; 1976.

9. Forsyth, J. P., Eifert, G. H. \& Canna, M. A. Evoking analogue subtypes of panic attacks in a nonclinical population using carbon dioxide-enriched air. Behav. Res. Ther. 38, 559-572 (2000).

10. Leibold, N. K. et al. $\mathrm{CO}_{2}$ exposure as translational cross-species experimental model for panic. Transl. Psychiatry 6, e885 (2016).

11. Vickers, K. \& McNally, R. J. Respiratory symptoms and panic in the National Comorbidity Survey: a test of Klein's suffocation false alarm theory. Behav. Res. Ther. 43, 1011-1018 (2005).

12. Breslau, N. \& Kessler, R. C. The stressor criterion in DSM-IV posttraumatic stress disorder: an empirical investigation. Biol. Psychiatry 50, 699-704 (2001).

13. Kessler, R. C., Chiu, W. T., Demler, O., Merikangas, K. R. \& Walters, E. E. Prevalence, severity, and comorbidity of 12-month DSM-IV disorders in the National Comorbidity Survey Replication. Arch. Gen. Psychiatry 62, 617-627 (2005). 
14. Holmes, A. \& Singewald, N. Individual differences in recovery from traumatic fear. Trends Neurosci. 36, 23-31 (2013)

15. Goodwin, R. D. et al. The epidemiology of panic disorder and agoraphobia in Europe. Eur. Neuropsychopharmacol. 15, 435-443 (2005).

16. Hettema, J. M., Neale, M. C. \& Kendler, K. S. A review and meta-analysis of the genetic epidemiology of anxiety disorders. Am. J. Psychiatry 158, 1568-1578 (2001).

17. Schumacher, J. et al. The genetics of panic disorder. J. Med. Genet. 48, 361-368 (2011).

18. Maron, E., Hettema, J. M. \& Shlik, J. Advances in molecular genetics of panic disorder. Mol. Psychiatry 15, 681-701 (2010).

19. Maron, E. et al. Association study of 90 candidate gene polymorphisms in panic disorder. Psychiatr. Genet. 15, 17-24 (2005).

20. Pollack, M. et al. A randomized controlled trial of venlafaxine ER and paroxetine in the treatment of outpatients with panic disorder. Psychopharmacology 194, 233-242 (2007a).

21. Pollack, M. H. et al. A double-blind study of the efficacy of venlafaxine extended-release, paroxetine, and placebo in the treatment of panic disorder. Depress Anxiety 24, 1-14 (2007b).

22. Lesch, K. P. et al. Association of anxiety-related traits with a polymorphism in the serotonin transporter gene regulatory region. Science 274, 1527-1531 (1996).

23. Little, K. Y. et al. Cocaine, ethanol, and genotype effects on human midbrain serotonin transporter binding sites and mRNA levels. Am. J. Psychiatry 155 207-213 (1998).

24. Heils, A. et al. Allelic variation of human serotonin transporter gene expression. J. Neurochem. 66, 2621-2624 (1996).

25. Garpenstrand, H., Annas, P., Ekblom, J., Oreland, L. \& Fredrikson, M. Human fear conditioning is related to dopaminergic and serotonergic biological markers. Behav. Neurosci. 115, 358-364 (2001).

26. Klumpers, F., Heitland, I., Oosting, R. S., Kenemans, J. L. \& Baas, J. M. Genetic variation in serotonin transporter function affects human fear expression indexed by fear-potentiated startle. Biol. Psychol. 89, 277-282 (2012).

27. Gressier, F. et al. The 5-HTTLPR polymorphism and posttraumatic stress disorder: a meta-analysis. J. Trauma. Stress 26, 645-653 (2013).

28. Blaya, C., Salum, G. A., Lima, M. S., Leistner-Segal, S. \& Manfro, G. G. Lack of association between the Serotonin Transporter Promoter Polymorphism (5HTTLPR) and Panic Disorder: a systematic review and meta-analysis. Behav. Brain. Funct. 3, 41 (2007).

29. Lonsdorf, T. B. et al. The symptomatic profile of panic disorder is shaped by the 5-HTTLPR polymorphism. Prog. Neuropsychopharmacol. Biol. Psychiatry 33, 1479-1483 (2009).

30. Henderson, L. A. et al. Real-time imaging of cortical areas involved in the generation of increases in skin sympathetic nerve activity when viewing emotionally charged images. Neuroimage 62, 30-40 (2012).

31. Johnson, P. L., Truitt, W. A., Fitz, S. D., Lowry, C. A. \& Shekhar, A. Neural pathways underlying lactate-induced panic. Neuropsychopharmacology 33, 2093-2107 (2008).

32. Brydges, N. M. et al. Imaging conditioned fear circuitry using awake rodent fMRI. PloS One 8, e54197 (2013).

33. Singewald, N., Salchner, P. \& Sharp, T. Induction of c-Fos expression in specific areas of the fear circuitry in rat forebrain by anxiogenic drugs. Biol. Psychiatry 53, 275-283 (2003).

34. Butler, R. K. et al. Activation of phenotypically-distinct neuronal subpopulations of the rat amygdala following exposure to predator odor. Neuroscience $\mathbf{1 7 5}$, 133-144 (2011).

35. Johansen, J. P., Cain, C. K., Ostroff, L. E. \& LeDoux, J. E. Molecular mechanisms of fear learning and memory. Cell 147, 509-524 (2011).

36. Johansen, J. P., Wolff, S. B., Luthi, A. \& LeDoux, J. E. Controlling the elements: an optogenetic approach to understanding the neural circuits of fear. Biol. Psychiatry 71, 1053-1060 (2012).

37. Hariri, A. R. et al. Serotonin transporter genetic variation and the response of the human amygdala. Science 297, 400-403 (2002).

38. Canli, T. et al. Neural correlates of epigenesis. Proc Natl Acad. Sci. USA 103 16033-16038 (2006).

39. Feinstein, J. S. et al. Fear and panic in humans with bilateral amygdala damage. Nat. Neurosci. 16, 270-272 (2013).

40. Wiest, G., Lehner-Baumgartner, E. \& Baumgartner, C. Panic attacks in an individual with bilateral selective lesions of the amygdala. Arch. Neurol. 63, 1798-1801 (2006).
41. Schruers, $\mathrm{K}$. et al. Genetic moderation of $\mathrm{CO}_{2}$-induced fear by 5 -HTTLPR genotype. J. Psychopharmacol. 25, 37-42 (2011).

42. Homberg, J. R. et al. Characterization of the serotonin transporter knockout rat: a selective change in the functioning of the serotonergic system. Neuroscience 146, 1662-1676 (2007).

43. Joeyen-Waldorf, J., Edgar, N. \& Sibille, E. The roles of sex and serotonin transporter levels in age- and stress-related emotionality in mice. Brain Res. 1286, 84-93 (2009).

44. Olivier, J. D. et al. A study in male and female 5-HT transporter knockout rats: an animal model for anxiety and depression disorders. Neuroscience $\mathbf{1 5 2}$ 573-584 (2008).

45. Truitt, W. A. et al. Ethanol and nicotine interaction within the posterior ventral tegmental area in male and female alcohol-preferring rats: evidence of synergy and differential gene activation in the nucleus accumbens shell. Psychopharmacology 232, 639-649 (2015).

46. Carnevali, L. et al. Different patterns of respiration in rat lines selectively bred for high or low anxiety. PLoS One 8, e64519 (2013).

47. Johnson, P. L. et al. Induction of c-Fos in 'panic/defence'-related brain circuits following brief hypercarbic gas exposure. J. Psychopharmacol. 25, 26-36 (2010).

48. Paxinos, G. \& Watson, C. The Rat Brain Stereotaxic Coordinates. (Academic Press, San Diego, 1997).

49. Molosh, A. I. et al. NPY Y1 receptors differentially modulate GABAA and NMDA receptors via divergent signal-transduction pathways to reduce excitability of amygdala neurons. Neuropsychopharmacology 38, 1352-1364 (2013).

50. Gorman, J. M. et al. Anxiogenic effects of $\mathrm{CO}_{2}$ and hyperventilation in patients with panic disorder. Am. J. Psychiatry 151, 547-553 (1994).

51. Pitts, F. N. Jr. \& McClure, J. N. Jr. Lactate metabolism in anxiety neurosis. N. Engl. J. Med. 277, 1329-1336 (1967).

52. Woods, S. W., Charney, D. S., Goodman, W. K. \& Heninger, G. R. Carbon dioxideinduced anxiety. Behavioral, physiologic, and biochemical effects of carbon dioxide in patients with panic disorders and healthy subjects. Arch. Gen. Psychiatry 45, 43-52 (1988a).

53. Nashold, B. S. Jr., Wilson, W. P. \& Slaughter, D. G. Sensations evoked by stimulation in the midbrain of man. J. Neurosurg. 30, 14-24 (1969).

54. Wilent, W. B. et al. Mapping of microstimulation evoked responses and unit activity patterns in the lateral hypothalamic area recorded in awake humans. Tech. Note J. Neurosurg. 115, 295-300 (2011).

55. Wilent, W. B. et al. Induction of panic attack by stimulation of the ventromedial hypothalamus. J. Neurosurg. 112, 1295-1298 (2010).

56. Bittencourt, A. S., Carobrez, A. P., Zamprogno, L. P., Tufik, S. \& Schenberg, L. C Organization of single components of defensive behaviors within distinct columns of periaqueductal gray matter of the rat: role of N-methyl-D-aspartic acid glutamate receptors. Neuroscience 125, 71-89 (2004).

57. Samuels, B. C., Zaretsky, D. V. \& DiMicco, J. A. Tachycardia evoked by disinhibition of the dorsomedial hypothalamus in rats is mediated through medullary raphe. J. Physiol. 538, 941-946 (2002).

58. Schenberg, L. C. \& Lovick, T. A. Neurones in the medullary raphe nuclei attenuate the cardiovascular responses evoked from the dorsolateral periaqueductal grey matter. Brain Res. 651, 236-240 (1994).

59. Shekhar, A. \& DiMicco, J. A. Defense reaction elicited by injection of GABA antagonists and synthesis inhibitors into the posterior hypothalamus in rats. Neuropharmacology 26, 407-417 (1987).

60. Grassi, M. et al. Baseline respiratory parameters in panic disorder: a metaanalysis. J. Affect Disord. 146, 158-173 (2013).

61. Johnson, P. L. et al. Orexin 1 and 2 receptor involvement in $\mathrm{CO}_{2}$-induced panic-associated behaviora and autonomic responses. Depression Anxiety $\mathbf{3 2}$ 671-683 (2015)

62. Johnson, P. L. et al. Induction of c-Fos in 'panic/defence'-related brain circuits following brief hypercarbic gas exposure. J. Psychopharmacol. 25, 26-36 (2011).

63. Johnson, P. L. et al. Activation of the orexin 1 receptor is a critical component of $\mathrm{CO}_{2}$-mediated anxiety and hypertension but not bradycardia. Neuropsychopharmacology 37, 1911-1922 (2012).

64. Zanoveli, J. M., Carvalho, M. C., Cunha, J. M. \& Brandao, M. L. Extracellular serotonin level in the basolateral nucleus of the amygdala and dorsal periaqueductal gray under unconditioned and conditioned fear states: an in vivo microdialysis study. Brain Res. 1294, 106-115 (2009).

65. Rainnie, D. G. Serotonergic modulation of neurotransmission in the rat basolateral amygdala. J. Neurophysiol. 82, 69-85 (1999). 
66. Amat, J., Matus-Amat, P., Watkins, L. R. \& Maier, S. F. Escapable and inescapable stress differentially alter extracellular levels of $5-\mathrm{HT}$ in the basolateral amygdala of the rat. Brain Res. 812, 113-120 (1998).

67. McDonald, A. J. \& Mascagni, F. Neuronal localization of 5-HT type 2A receptor immunoreactivity in the rat basolateral amygdala. Neuroscience 146, 306-320 (2007).

68. Aznar, S., Qian, Z., Shah, R., Rahbek, B. \& Knudsen, G. M. The 5-HT1A serotonin receptor is located on calbindin- and parvalbumin-containing neurons in the rat brain. Brain Res. 959, 58-67 (2003).

69. Li, X. et al. 5-HT1A receptor agonist affects fear conditioning through stimulations of the postsynaptic 5-HT1A receptors in the hippocampus and amygdala. Eur. J. Pharmacol. 532, 74-80 (2006).

70. Morrison, K. E. \& Cooper, M. A. A role for 5-HT1A receptors in the basolateral amygdala in the development of conditioned defeat in Syrian hamsters. Pharmacol. Biochem. Behav. 100, 592-600 (2012).

71. Burghardt, N. S., Bush, D. E., McEwen, B. S. \& LeDoux, J. E. Acute selective serotonin reuptake inhibitors increase conditioned fear expression: blockade with a 5-HT(2C) receptor antagonist. Biol. Psychiatry 62, 1111-1118 (2007).

72. Do-Monte, F. H., Manzano-Nieves, G., Quinones-Laracuente, K., Ramos-Medina, L. \& Quirk, G. J. Revisiting the role of infralimbic cortex in fear extinction with optogenetics. J. Neurosci. 35, 3607-3615 (2015).
73. Quirk, G. J., Likhtik, E., Pelletier, J. G. \& Pare, D. Stimulation of medial prefrontal cortex decreases the responsiveness of central amygdala output neurons. J. Neurosci. 23, 8800-8807 (2003)

74. Santini, E., Ge, H., Ren, K., Pena de Ortiz, S. \& Quirk, G. J. Consolidation of fear extinction requires protein synthesis in the medial prefrontal cortex. J. Neurosci. 24, 5704-5710 (2004).

75. Santini, E., Quirk, G. J. \& Porter, J. T. Fear conditioning and extinction differentially modify the intrinsic excitability of infralimbic neurons. J. Neurosci. 28, 4028-4036 (2008)

76. Johnson, P. L. et al. Pharmacological depletion of serotonin in the basolateral amygdala complex reduces anxiety and disrupts fear conditioning. Pharmacol. Biochem. Behav. 138, 174-179 (2015b).

77. Nash, J. R. et al. Serotonin 5-HT1A receptor binding in people with panic disorder: positron emission tomography study. Br. J. Psychiatry 193, 229-234 (2008).

78. Neumeister, A. et al. Reduced serotonin type $1 \mathrm{~A}$ receptor binding in panic disorder. J. Neurosci. 24, 589-591 (2004).

79. Wellman, C. L. et al. Impaired stress-coping and fear extinction and abnormal corticolimbic morphology in serotonin transporter knock-out mice. J. Neurosci. 27, 684-691 (2007). 